\title{
Infrastructures for Education, Research and Industry in Microelectronics - Recent Developments
}

\author{
B. Courtois, K. Torki, S. Colin, H. Delori, S. Eyraud, J-F Paillotin, G. di Pendina, S. Dumont \\ CMP Service - 46 avenue Félix Viallet - 38031 Grenoble Cedex - France, E-mail: Bernard.Courtois@imag.fr
}

\begin{abstract}
Infrastructures to provide access to custom integrated hardware manufacturing facilities are important because they allow Students and Researchers to access professional facilities at a reasonable cost, and they allow Companies to access small volume production, otherwise difficult to obtain directly from manufacturers. This paper is reviewing the most recent developments at CMP like the introduction of a CMOS $65 \mathrm{~nm}$ process, and the cooperation between the major infrastructures services available worldwide.
\end{abstract}

\section{THE NEED FOR INFRASTRUCTURES}

Infrastructures to provide access to custom integrated hardware manufacturing facilities are important for several reasons:

- they allow Students and Researchers to access professional facilities at a reasonable cost,

- they allow Companies to access small volume production, otherwise difficult to obtain directly from manufacturers.

The needs of Universities, Research Laboratories and Companies can be summarized as follows:

- Universities need to have access to technology for teaching their students. Those students will be in the industry. Therefore they have to be trained at least on the actual state of the art technology processes.

- Research Laboratories usually need to have high performance technologies to validate new concepts. The quality of the research results depends mostly on the quality of the technologies. Accessing to up to date technologies is a necessity.

- Industrial users also need to access to the state of the art of the offered technologies. This is vital for industrial users. The development of a product is usually long (more than 1 or 2 years). It is necessary that an industrial user has access to an up to date process, giving guaranty on product life.

Offering manufacturing Services has to be governed by the following basic principles:

- industrial quality process lines should be used (University process lines cannot offer a stable yield),

- design kits to link CAD and MPC/MPW facilities should be offered to ease the design.

It is also to be noted that almost every country or continent is a high cost country or continent to another one at the time of global markets. It is thus important to keep students, researchers, industrialists ahead of others in order to stay in business. To stay ahead means to train, research, use, advanced design methods and tools and to design on advanced processes.

\section{DEVELOPMENTS AT CMP}

A review of early national efforts can be found in [1], and a review of first cooperative initiatives may be found in [2].

Since 1981 several periods may be distinguished, starting from a NMOS process in 1981 to the introduction of a $65 \mathrm{~nm}$ CMOS process in late 2005 .

Processes available: Presently the processes available for ICs and MEMS manufacturing are depicted in Table 1.

\begin{tabular}{|c|c|}
\hline \multirow[t]{6}{*}{ Austriamicrosystems } & $0.35 \mu$ CMOS C35B4C3 \\
\hline & $0.35 \mu$ CMOS C35B4M3 \\
\hline & $0.35 \mu$ CMOS-Opto C35B4O1 \\
\hline & $0.35 \mu$ CMOS Flash C35B4E3 \\
\hline & $0.35 \mu$ SiGe BiCMOS S35D4M5 \\
\hline & $0.35 \mu$ HV-CMOS H35B4D3 \\
\hline \multirow[t]{5}{*}{ STMicroelectronics } & $0.12 \mu$ CMOS HCMOS9GP \\
\hline & 90nm CMOS CMOS090 \\
\hline & $65 \mathrm{~nm}$ CMOS CMOS065 \\
\hline & $0.35 \mu$ SiGe BiCMOS BiCMOS6G \\
\hline & $0.25 \mu \mathrm{SiGe}: \mathrm{C}$ BiCMOS7RF \\
\hline \multirow[t]{2}{*}{ OMMIC } & $0.2 \mu$ HEMT GaAs ED02AH \\
\hline & $0.2 \mu$ HEMT GaAs ED02AH Bulk Micromachining \\
\hline \multirow[t]{4}{*}{ MEMSCAP } & ASIMPS CMOS + DRIE \\
\hline & PolyMUMPs \\
\hline & SOI MUMPs \\
\hline & Metal MUMPs \\
\hline \multirow[t]{2}{*}{ CSMC } & $0.6 \mu \mathrm{CMOS} 2 \mathrm{P} / 2 \mathrm{M} / \mathrm{HR}$ \\
\hline & $0.6 \mu \mathrm{CMOS} 2 \mathrm{P} / 2 \mathrm{M} / \mathrm{HR}$ Bulk Micromachining \\
\hline
\end{tabular}

TABLE 1:CMP IC AND MEMS PROCESSES AVAILABLE

ICs design kits and CAD software: Design kits and libraries are distributed by CMP for most of the processes and most commonly used CAD tools. CMP sometimes develop design kits, in cooperation with the manufacturers and the CAD vendors. CMP also offers special CAD software conditions from a few CAD vendors. As a focal point, CMP also distributes information on configuration files, converters, etc. About 40 design kits are available for each process and the main CAD tools. 
from the research institutes as well as domestic industrial sectors.

CMC: CMC Microsystems (www.cmc.ca) provides national infrastructure for microsystems research and technology development, accelerating Canadian competitiveness through the development of highly qualified people and the commercial advancement of research. Established in 1984 as a not-for-profit corporation, CMC manages a major five-year grant awarded by the Natural Sciences and Engineering Research Council of Canada (NSERC), matched by industrial contributions. For the period 2005-2010, CMC directs a national program valued at over \$110 million (including cash and in-kind contributions). In terms of fabrication services, CMC offers the following (Table $5)$ :

\begin{tabular}{|l|l|}
\hline 90-nm CMOS & STMicroelectronics through CMP \\
\hline $0.13 \mu \mathrm{CMOS}$ & IBM through MOSIS \\
\hline $0.18 \mu \mathrm{CMOS}$ & TSMC through MOSIS \\
\hline $0.35 \mu \mathrm{CMOS}$ & TSMC through MOSIS \\
\hline $0.5 \mu \mathrm{SiGe}$ BiCMOS, 5AM \& 5HP & TSMC through MOSIS \\
\hline $\begin{array}{l}0.8 \mu \mathrm{CMOS} \text { in three process flavors: } \\
\text { high-voltage--up to 300V, mid-voltage } \\
\text { range--+/-20V, and standard-voltage-- } \\
2.7 \mathrm{~V} \text { to 5.5V }\end{array}$ & DALSA Semiconductor \\
\hline $2.5 \mathrm{GHz}$ Bipolar linear array & Gennum Corporation \\
\hline $\begin{array}{l}\text { PolyMUMPs surface micromachining } \\
\text { process }\end{array}$ & MEMSCAP through CMP \\
\hline MetalMUMPs & MEMSCAP through CMP \\
\hline $\begin{array}{l}\text { Micragem SOI-based micromachining } \\
\text { process }\end{array}$ & $\begin{array}{l}\text { Micralyne Generalized MEMS } \\
\text { process }\end{array}$ \\
\hline $\begin{array}{l}\text { Protolyne for semi-custom microfluidics } \\
\text { device }\end{array}$ & $\begin{array}{l}\text { Micralyne Generalized MEMS } \\
\text { process }\end{array}$ \\
\hline $\begin{array}{l}\text { Protolyne for semi-custom microfluidics } \\
\text { devices }\end{array}$ & Micralyne \\
\hline Photonics/optoelectronics & $\begin{array}{l}\text { through Canadian Photonics } \\
\text { Fabrication Centre }\end{array}$ \\
\hline
\end{tabular}

TABLE 5: CMC IC AND MEMS PROCESSES AVAILABLE

A total of 403 designs were fabricated in 2006 using the technologies listed above.

ICC: Founded in 2000 by Science and Technology Commission of Shanghai Municipality, Shanghai Research Center for Integrated Circuit Design (so-called ICC) is dedicated in promoting Shanghai and all China IC Design industry to realize durative rapid development. ICC established the public service platform open to all IC design enterprises, universities and research institutes, providing full services to improve design quality and lower the cost. The services ICC provides include Multi-Project Wafer service, SoC design platform, testing service, training and evaluation, information service, etc. From 1996 to 2000, Shanghai MPW Service (SMS), operated by Fudan University, was mainly open to academic users. From 2001, ICC began to operate SMS, expanded the service to industrial sectors and became the China National MPW Center. Totally 761 designs from more than 250 design houses, universities and research institutes were prototyped on MPW runs and low volume production since 2001. In 2006, the process technologies are listed in Table 6.

\begin{tabular}{|l|}
\hline CSMC 0.6um CMOS \\
\hline Chartered 0.35um CMOS \\
\hline Chartered 0.25 um CMOS \\
\hline Chartered 0.35um SiGe \\
\hline TSMC 0.18um CMOS \\
\hline TSMC 0.25um CMOS \\
\hline TSMC 0.35um CMOS \\
\hline SMIC 0.18um CMOS \\
\hline SMIC 0.35um EEPROM \\
\hline HJTC 0.18um CMOS \\
\hline HJTC 0.25um CMOS \\
\hline HJTC 0.25um EEPROM \\
\hline TABLE 6: ICC IC PROCESSES AVAILABLE
\end{tabular}

There are totally 22 runs in the year of 2006. 101 chips from 63 customers were successfully fabricated. Among those, 54 were industrial projects, the remaining 47 were educational and research projects. In 2006, ICC provided an SoC design support platform with the cores from ARM, ZSP, and Synopsys, such as ARM7TDMI, ARM926EJ, NEO, ZSP200, ZSP400.

IDEC: IDEC (Integrated Circuit Design Education Center) was launched in 1995 with the support of the Ministry of Commerce, Industry and Energy and major semiconductor industries for the purpose of educating designers in the nonmemory IC field. The objectives of IDEC include (a) buildingup and strengthening the infrastructure of VLSI design education; (b) training highly-qualified VLSI system designers; and (c) contributing to Korean semiconductor industries by promoting collaborations between universities and industries. Currently, IDEC provides MPW services for 62 WGs (Working Groups) in Korea. As of January 2007, a total of 1,814 IC chips have been successfully fabricated through the IDEC MPW (Multi-Project Wafer) program. The technologies being provided in 2007 are listed in Table 7:

\begin{tabular}{|l|l|}
\hline CMOS 0.35 $\mu, 1$-poly 4-metal & Samsung Electronics \\
\hline CMOS 0.18 $\mu, 1$-poly 4-metal & Samsung Electronics \\
\hline CMOS 0.35 $\mu, 2$-poly 4-metal & Magnachip/Hynix \\
\hline CMOS 0.18 $\mu, 1$-poly 6-meta & Magnachip/Hynix \\
\hline CMOS 0.18 $\mu, 1$-poly 6-metal & Dongbu Electronics \\
\hline InGaP HBT & Knowledge-on \\
\hline
\end{tabular}

TABLE 7: IDEC IC PROCESSES AVAILABLE

The students who fabricate chips using IDEC MPW Service are required to give posters/demo presentations in the IDEC Chip Design Contest.

MOSIS: MOSIS is a low-cost prototyping and small volume production service for VLSI circuit development with a worldwide customer base. Since 1981, the service has fabricated more than 50,000 integrated circuit designs for use by commercial firms, government agencies and universities and has served as the model for similar operations throughout the world. It is a not-for-profit organization started in 1980 by 
DARPA (Defense Advanced Research Projects Agency of the U.S. Department of Defense) at the Information Sciences Institute to provide their research community with access to advanced IC fabrication lines in a cost effective manner. In 1986, the service was further expanded to include U.S. commercial firms and in 1995 to include both commercial firms and educational institutions outside the U.S. Since 1994, MOSIS has been entirely self-supported, deriving all of its revenue from commercial operations. The processes available today from MOSIS are listed in Table 8.

\begin{tabular}{|l|l|}
\hline Agilent/HP (Avago) & $0.5 \mu$ CMOS \\
AMI Semiconductor & $0.35 \mu, 0.5 \mu, 0.7 \mu, 1.5 \mu$ CMOS \\
\hline IBM & $90 \mathrm{~nm}, 0.13 \mu, 0.18 \mu$ and $0.25 \mu$ CMOS \\
& $0.13 \mu, 0.18 \mu, 0.25 \mu, 0.35 \mu$ and $0.5 \mu$ \\
& SiGe BiCMOS \\
\hline TSMC & $0.13 \mu, 0.18 \mu, 0.25 \mu, 0.35 \mu$ CMOS \\
\hline Austriamicrosystems through & $0.35 \mu$ CMOS; 0.35 $\mu$ HV CMOS \\
CMP & $0.35 \mu$ SiGe BiCMOS \\
\hline
\end{tabular}

CMOS-compatible MEMS technologies are also available.

VDEC: VLSI Design and Education Center (VDEC), which is located in the University of Tokyo, has been utilized by academic users in Japan since its foundation in May, 1996. As an MPC service center, VDEC aims at improvements of education on VLSI design and supports on VLSI chip fabrication for national universities, public universities, private universities and colleges in Japan. VDEC receives a lot of supports from Japan government, as well as semiconductor industries through STARC (Semiconductor Technology Academic Research Center). Presently the following technologies are available for chip fabrication service Table 9.

\begin{tabular}{|l|l|}
\hline 2-poly 2-metal CMOS $1.2 \mu$ & SCG Japan Ltd (OnSemiconductor Ltd) \\
\hline 2-poly 3-metal CMOS $0.35 \mu$ & Rohm Co. Ltd \\
\hline 1-poly 5-metal CMOS $0.18 \mu$ & Rohm Co. Ltd \\
\hline 1-poly 5-metal CMOS $0.18 \mu$ & Hitachi Ltd \\
\hline 2-metal 0.8 $\mu$ bipolar & NEC Compound Semicond Devices Ltd \\
\hline 1-poly 5-metal CMOS-SOI 0.15 $\mu$ & Oki Electric \\
\hline 1-poly 6-metal CMOS $90 \mathrm{~nm}$ & ASPLA \\
\hline VDEC-MOSIS CMOS $0.25 \mu / 0.18 \mu$ & TSMC \\
\hline VDEC-MOSIS Si-Ge BiCMOS $0.5 \mu$ & IBM \\
\hline
\end{tabular}

TABLE 9: VDEC PROCESSES AVAILABLE

Totally 445 chips on $6154 \mathrm{~mm}^{2}$ silicon area were designed and fabricated in the last fiscal year (2005.4-2006.3). Besides, since 2003, some MOSIS chip fabrication technologies, such as TSMC $0.18 \mu, 0.25 \mu$ CMOS and IBM $0.5 \mu$ Si-Ge BiCMOS, have been provided to VDEC users at a lower cost based on a close VDEC-MOSIS cooperative relationship.

\section{EXPANDING TO PCBS AND MEMS}

CMP and MOSIS offered long ago to expand services to PCBs, but it seems that the needs were less important in this area. CMP also offered MCMs, but the offer was not taken very well. Another move has been very important: the expansion to
MEMS. CMP offered manufacturing for MEMS as early as 1995, being the first service to offer MEMS. Since then the portfolio has been largely expanding and today CMC-CMPMOSIS offer MEMS manufacturing, including the PolyMUMPS, MetalMUMPS and SOIMUMPS from MEMSCAP. These 3 services enjoy a 10 years MEMS experience, obtained through 69 runs, 198 designs. It is important that MEMS can be obtained from the same services delivering ICs, so that integration (either at the packaging level or at the die level) is made easier.

\section{PRESENT COOPERATIVE EFFORTS}

Presently, the major cooperative effort is undertaken by CMC, CMP and MOSIS. These 3 infrastructure services announced it at DAC in June 2002. Since then, the cooperation has been steadily expanding [3]. Separately, CMP has also set up a number of bilateral cooperation with infrastructure services, with special groups in various countries, and has established distributors in several parts of the world.

\section{CONCLUSIONS}

A few trends and comments may conclude. The major services are going global in terms of cooperation, acting worldwide. The more advanced services are also going global in terms of technologies, addressing in the future electronics, photonics, mechanics, fluidics, as CMC-CMP-MOSIS plan to do. It is worth to note that the 7 major infrastructure services share the same legal status (services hosted by a University). The most advanced of these services shared the same development in extending their services from Universities to Companies and evolving from a subsidized service (by Ministries, Agencies, etc.) to a non-profit non subsidized kind of service.

\section{REFERENCES}

[1] "MPC Services available worldwide", invited paper, APCCAS'94 IEEE Asia-Pacific Conference on Circuits and Systems, December 5-8 1994, Grand Hotel, Taipei, Taiwan.

[2] "Infrastructures for Education and Research: from National Initiatives to Worldwide Development", invited talk, Technical University of Darmstadt, M. GLESNER 60th birthday ceremony, 29 August 2003.

[3] CMC, CMP \& MOSIS, "The Scale of Cooperation Increases as the Dimensions of Microchips Decrease", invited paper, $3^{\text {rd }}$ International Conference on MSE, 1-2 June 2003, Anaheim, USA. 